\title{
Interface gráfica de Tabela Periódica Interativa no contexto de uma educação bilíngue (LIBRAS/Português)
}

Graphic interface of Interactive Periodic Table in the context of bilingual education (LIBRAS/Portuguese)

Francine Medeiros Vieira ${ }^{1}$

Gilson Braviano ${ }^{2}$

Berenice Santos Gonçalvez ${ }^{3}$ 


\section{Resumo}

Este artigo tem como objetivo apresentar um estudo para o desenvolvimento de uma Tabela Periódica Interativa com foco na Língua Brasileira de Sinais (LIBRAS) que contribua com o processo de ensino-aprendizagem de alunos surdos na disciplina de Química. A pesquisa parte da revisão bibliográfica e das recomendações preexistentes de materiais para surdos, sugeridas por Lapolli (2014), seguida de pesquisa exploratória e de inspeção analítica de tabelas periódicas similares, conforme os critérios de avaliação de interfaces gráficas sugeridos por Gui Bonsiepe (2011). Os resultados obtidos até o presente momento apontam requisitos para a construção e a disponibilização na internet de uma Tabela Periódica, como recurso didático, que facilite a visualização das informações no contexto de uma educação bilíngue.

Palavras-chave: Interface gráfica, Design de Informação, educação de surdos

\section{Abstract}

This article aims to present the beginning of a study to develop an Interactive Periodic Table focused on the Brazilian Language of Signals (LIBRAS) that contributes to the teaching-learning process of deaf students in the discipline of chemistry. The research is based on the literature review and the pre-existing recommendations for materials for the deaf, suggested by Lapolli (2014), followed by the exploratory research and the analytical inspection of similar periodic tables, according to the graphical user interface evaluation criteria suggested by Gui Bonsiepe (2011). The results obtained so far point to requirements for the construction and availability on the Internet of a Periodic Table as a didactic resource that facilitates the visualization of information in the context of a bilingual education.

Key-words: graphical interface, information design, deaf education

ISSN: 2316-7963

${ }^{1}$ Mestranda em Design, UFSC (francinemedeiros@gmail.com)

2 Doutor em Matemática Aplicada, UFSC

${ }^{3}$ Doutora em Engenharia, UFSC 


\section{Introdução}

A facilidade em interagir virtualmente, acessar e disseminar informações, proporcionada pelo avanço da internet, pelo Design e pelo uso das Tecnologias da Informação e Comunicação (TICs) na Educação tem contribuído com os processos de ensino-aprendizagem e de construção do conhecimento da maioria dos alunos. Entretanto, a disponibilização de informações e materiais didáticos baseados apenas na língua portuguesa - oral e escrita -, sem um estudo inclusivo no campo da visualidade e do bilinguismo, tem dificultado o desenvolvimento do aluno surdo e o excluindo, em parte, dessa evolução tecnológica nas atividades educacionais.

O aluno surdo tem na visão sua maior percepção para a aprendizagem. O uso da LIBRAS, fundamentado na espacialidade e na capacidade de configurações das mãos, confere-lhe sua fluência linguística. Já na comunicação oral, por exemplo, em sala de aula, nos vídeos tutoriais na internet, nas videoaulas de cursos a distância, nos poadcasts didáticos e em textos extensos, poucos recursos alcançam o aluno surdo, formando barreiras na comunicação e na sua aprendizagem.

No cotidiano do campus Palhoça Bilíngue, as experiências e as dificuldades em sala de aula e no Ambiente Virtual de Aprendizagem (Moodle) entre surdos e ouvintes têm mobilizado diariamente discussões acerca da necessidade de inserir a LIBRAS, de alguma maneira, em todas as informações e materiais disponibilizados como site, notícias, menus de acesso, convites de eventos, intranet, atividades etc.

A preocupação em tornar a informação o mais acessível possível ao aluno surdo, encampada pelos profissionais (docentes e técnicos-administrativos) do campus, é a diretriz da proposta de bilinguismo, que está sendo construída e motivada pela falta de materiais didáticos bilíngues que atendam às especificidades desse aluno nas distintas áreas de conhecimentos dos cursos ofertados.

A produção de recursos bilíngues para facilitar o processo didático de aquisição de conhecimento, mediante o estudo de interfaces, ainda deve ser explorada no âmbito da pesquisa. Nessa direção, este artigo objetiva apresentar o início do desenvolvimento de uma Tabela Periódica Interativa Bilíngue como um material didático para a disciplina de Química no ensino médio, com vistas a potencializar a aprendizagem de alunos surdos num contexto real.

\section{Educação de surdos}

Segundo o Plano Nacional de Educação, com vigência de 2014 a 2024, está garantida a inclusão dos alunos com deficiência na escola regular, bem como a criação e a manutenção de escolas bilíngues pelo governo. Porém, a educação bilíngue ainda está em construção e sua prática se mostra ambivalente no que se refere às filosofias anteriores, pois, segundo Morais, Ferretti e Machado (2012: 23), “[...] as práticas docentes regidas pela filosofia oralista construíram, em quase um século de opressão, uma história de fracassos na educação de surdos".

Nessa linha, Ramirez e Masutti (2009: 25) corroboram que "[...] acessar o mundo letrado através das propostas educacionais existentes tem sido um árduo caminho para a ampla maioria de surdos", pois as barreiras formadas na comunicação, ora pelas 
exigências da oralização, ora pela necessidade do domínio da escrita da língua portuguesa, dificultaram o desenvolvimento cognitivo desses alunos e os excluem dos processos pedagógicos.

Apesar de o atual reconhecimento da LIBRAS e a conquista do aluno surdo pelo direito de ter um tradutor/intérprete em sala de aula terem propiciado o início da inclusão dos surdos nos sistemas educacionais, muitas vezes, a falta de domínio do conteúdo e do vocabulário dos termos técnicos da disciplina pelo profissional da Tradução e Interpretação também fragiliza a mediação da informação e consequentemente prejudica o aprendizado desses alunos. Além disso, ainda pesam contra a educação dos surdos a falta de materiais didáticos específicos e o preparo do professor para lidar com as diferenças.

Nesse contexto, a educação bilíngue surge para promover a compreensão das diferenças culturais dos surdos e desmistificar conceitos e preconceitos na sua formação, uma vez que persiste, em boa parte da sociedade, a ideia errônea de uma representação do ouvinte como indivíduo normal e perfeito, e o surdo como indivíduo a ser moldado e integrado, de maneira impositiva, aos padrões culturais 'ovintistas' (SKLIAR, 1999: 6).

Segundo Silva (2001: 53), "[...] o bilinguismo parte do princípio de que o surdo deve dominar, enquanto língua materna, a língua de sinais, que é a sua língua natural, e como segunda língua a língua oficial de seu país". Portanto, na perspectiva bilíngue, a educação de surdos deve priorizar a língua de sinais e a cultura dos sujeitos surdos em seu processo de aprendizagem. O português, por sua vez, deve ser assumido em seu status de segunda língua e ser submetido ao processo extremamente complexo de tradução para as modalidades de línguas visuais (MACHADO, 2009; RAMIREZ; MASUTTI, 2009).

Assim, Fernandes e Rios (1998: 18) efetivam a perspectiva bilíngue conceituando o processo educacional como

[...] um processo no qual a integração deixa de ser a busca de integrar o surdo à comunidade de ouvintes, para caracterizar-se como uma via de mão dupla: estar o surdo bem integrado em sua própria comunidade e na comunidade de ouvintes e estarmos todos nós, que com eles convivemos, integrados, do mesmo modo, nas duas comunidades.

Por fim, a integração entre as duas línguas, LIBRAS e português, com predominância da primeira para o surdo, garante "um ambiente linguístico adequado, tanto no contexto familiar como no social" (SILVA, 2001: 54), que deve ser estendido às interfaces gráficas visando contribuir com a consolidação da cultura bilíngue mediante o desenvolvimento de materiais mais acessíveis.

\subsection{O campus Palhoça Bilíngue (LIBRAS/Português) e a Química}

O campus Palhoça do IFSC é o primeiro da Rede Federal de Educação Profissional e Tecnológica na modalidade bilíngue (LIBRAS/Português) no Brasil. Os cursos ofertados ocorrem em diferentes níveis e modalidades de ensino e atendem, principalmente, a alunos surdos e ouvintes da região da Grande Florianópolis. 
O bilinguismo, que está sendo construído, aprimorado e aplicado no campus, além de considerar a LIBRAS como a primeira língua do aluno surdo, promove a aprendizagem dessa língua por parte dos alunos ouvintes, motiva a formação bilíngue dos professores e capacita os profissionais para atuar na área da Tradução e Interpretação. Assim, o ensino de surdos e ouvintes dentro do campus representa a possibilidade de comunicação e interação contínua entre eles. Os alunos e os servidores aprendem na troca de experiências pessoais e profissionais, e são instruídos a buscar compreender e respeitar as especificidades de cada um e suas diferenças culturais (MACHADO, 2009).

A proposta pedagógica do campus dividiu os cursos em dois itinerários formativos: o bilíngue e a multimídia. O primeiro itinerário abrange cursos como LIBRAS e Português para surdos. Já o segundo itinerário, multimídia, contempla cursos nas áreas de Informática, Audiovisual e Design. A grande área de Multimídia tem um papel importante em torno dessa realidade, uma vez que se ocupa das questões gráficas de representação da informação que são relevantes nas experiências visuais dos surdos.

O ensino de Química no campus é lecionado no curso de ensino médio técnico em Comunicação Visual, pertencente ao itinerário de Multimídia. E, para que esse seja facilitado aos alunos, têm-se buscado estratégias visuais de ensino, com o uso da LIBRAS, em sala de aula pelo intérprete e pelo professor da disciplina para a produção de materiais impressos. Porém, a escassez de traduções de termos técnicos complexos da área da Química para a LIBRAS tem dificultado a aprendizagem e as interações dos alunos com o conteúdo novo que lhes é apresentado, pois eles não possuem o vocabulário necessário para a compreensão da matéria ministrada (SALDANHA, 2011).

Pesquisadores como Costa (2014) identificaram essas lacunas e carências no ensino da Química e, preocupados com essa realidade, têm publicado trabalhos de tradução de terminologias que podem contribuir com a melhoria do ensino da disciplina em escolas bilíngues e inclusivas. Segundo o pesquisador,

[...] na linguagem científica da química, átomos são vistos como sistemas solares em miniaturas, moléculas como bolas de bilhar e substância como caixinhas de surpresas prontas para liberarem a energia que têm guardadas, isto dificulta o processo de abstração tanto pelos alunos surdos quanto pelos ouvintes. (COSTA, 2014: 26).

Assim, a compreensão de textos em português que fazem uso de simbologia e termos específicos da Química para os surdos, como fórmulas, elementos químicos, processos químicos, átomo, volume, massa etc., torna-se maçante, complexa e desinteressante. Portanto, devem-se gerar discussões constantemente sobre a tradução dos termos para LIBRAS e a importância de aliar as estratégias de ensino com a criação de glossários de sinais para contextualizar o aluno nas temáticas das aulas (SALDANHA, 2011).

Com isso, o estudo deste artigo se caracteriza como um desafio real, pois visa contribuir com a consolidação do ensino bilíngue no contexto apresentado, motivado pela necessidade de buscar estratégias visuais de ensino de inserção da LIBRAS e pela falta de materiais didáticos próprios que auxiliem o ensino de Química no curso de ensino médio ofertado. 


\section{Interface gráfica acessível e o Design da Informação}

Interfaces gráficas desenvolvidas para surdos devem contemplar soluções técnicas, visuais e linguísticas de forma atrelada e em conformidade com as especificidades culturais desse público. Entender a cultura do surdo e promover espaços que valorizem a sua língua, escrita (SignWriting ${ }^{1}$ ) e sinalizada, representa a criação de condições distintas de acesso aos dados e às informações.

Nesse contexto o ambiente bilíngue é capaz de gerar uma aproximação entre ouvintes e surdos, favorecendo a internalização do sentimento de pertencimento.

A temática do sentimento de pertencimento tem ainda sua atualidade e sua complexidade marcadas pela presença dos meios de comunicação atuando no imaginário social, nas diferentes formas de organização da vida individual e coletiva, na delimitação e criação de interesses que os condicionam. As diferentes mídias podem, pois, estar atuando como mediação fundamental tanto na construção quanto na caracterização do pertencimento como linguagem de busca de identidade no contexto de um ausente comum aglutinador. (SOUSA, 2010: 4).

Assim, a condição de pertencimento para o surdo, portanto, só será possível se as interações sociais forem reais para além da presença física, partilhando-se da mesma língua, das mesmas experiências de mundo e vivências cotidianas. $O$ surdo precisa se sentir parte da história que é diariamente narrada nos livros, na televisão e na internet.

O design enquanto atividade projetual e interdisciplinar, responsável, principalmente, por gerar informações significativas mediante elementos gráficos e interativos, tem em sua metodologia as ferramentas necessárias para investigar e constituir um cenário mais perto do ideal para a educação do surdo no campo da visualidade. Isso porque a maneira como os elementos, o texto e a imagem são organizados na interface afeta o modo como o conteúdo é recebido pelos usuários (AMBROSE, 2012).

Ainda sobre esse assunto, Ambrose (2012: 45) afirma que "[...] o design deve ser estruturado para alcançar um determinado objetivo, seja informar, entreter ou guiar o leitor" numa linguagem conhecida. Dessa forma, a articulação entre o design e o bilinguismo permite ampliar as possibilidades de ensino e aprendizagem de maneira mais eficaz, conduzindo a crença de que, segundo Lapolli (2014: 196),

[...] é necessário que as informações e conteúdos sejam adaptados à maneira de perceber do surdo, fazendo com que ele interaja ou busque aquilo que necessita para sentir-se cômodo e, consequentemente, para que tenha uma melhor compreensão.

O campo de estudo que se preocupa com a acuidade visual e a compreesão das informações verbais e não verbais é o Design da Informação (FRASCARA, 2004). Para Horn (2000:15), o Design da Informação é definido como "[...] a arte e a ciência de preparar a informação para que ela possa ser usada por seres humanos com eficiência e eficácia". Segundo o mesmo autor, os dois objetivos principais desse campo de

1 O SignWriting (SW) é um sistema secundário de representação de informação linguística escrita baseado no sistema primário que é a língua de sinais, nesse caso a Língua Brasileira de Sinais. 
estudos são (1) desenvolver documentos que sejam compreensíveis, precisamente recuperáveis e fácil de traduzir em ação efetiva; e (2) projetar interações com equipamentos que sejam fáceis, naturais e tão agradáveis quanto possível.

O objetivo, portanto, do Design da Informação é o de assegurar, com base na especificidade do público, a efetividade da comunicação, facilitando processos de percepção, leitura, compreensão, memorização e uso da informação de forma acessível (FRASCARA, 2004). Nesse sentido, Lapolli (2014) sugere algumas recomendações para o desenvolvimento de infografias direcionadas ao público surdo que se enquadram em produtos hipermidiáticos no geral e contribuem com a construção de alternativas acessíveis. São eles:

- utilizar predominantemente imagens de qualquer tipo, mas equilibrar o uso para não poluir o ambiente, causando sobrecarga cognitiva de seus usuários com imagens meramente decorativas que não contribuem com a compreensão do conteúdo;

- usar imagem associada a textos curtos, pois possibilita o acesso a uma informação completa. O ideal é diminuir o máximo possível a quantidade de textos em português;

- traduzir para LIBRAS todos os textos do material mesmo que sejam curtos, pois, quando a pessoa fica com alguma dúvida em relação ao texto, pode recorrer à tradução;

- exibir a janela da tradução em LIBRAS num tamanho que permita visualizar bem os movimentos das mãos e a expressão facial do intérprete da língua de sinais. $\mathrm{E}$ possibilitar o aumento ou modo tela cheia da caixa de tradução;

- verificar com o público ao qual é destinado o material se é melhor que os sinais sejam gravados em fundo chromakeye para posteriormente o intérprete ser inserido no ambiente com fundo transparente, de maneira mais integrada com a interface;

- utilizar a soletração de uma palavra apenas uma vez. Nesse sentido, como o acesso nas infografias hipermidiáticas ocorre, geralmente, de forma não linear, não sendo possível saber qual vídeo será acessado primeiro, a solução é fazer um glossário em LIBRAS. No glossário, a palavra soletrada e com a legenda ganha um sinal e uma explicação. Assim, nos vídeos da infografia pode aparecer somente esse sinal e, se o usuário surdo tiver dúvidas em relação a um termo e/ou seu sinal, pode recorrer ao glossário;

- realizar a tradução para o SignWriting a partir da LIBRAS, pois, mesmo sendo uma das escritas mais bem aceitas pela comunidade surda, ainda é pouco difundida;

- permitir o compartilhamento de textos, vídeos e imagens (como chats), pois é importante para a comunicação quando se trabalha com ferramentas de interação entre os usuários surdos de um ambiente hipermídia. Um aviso visual deve ser dado cada vez que uma nova mensagem ou arquivo é recebido;

- padronizar o posicionamento dos elementos (textos, imagens, animações, vídeos etc.) para que os usuários possam facilmente identificar a localização dos conteúdos e suas traduções ao navegar pelo ambiente; e

- incluir diversão nas infografias hipermidiáticas de forma simples, leve, dinâmica, criativa, lúdica e atrativa para despertar a curiosidade e a vontade de interagir dos usuários. 


\section{Análises de Tabelas Periódicas Interativas}

O método aplicado para o desenvolvimento deste estudo foi a realização de uma pesquisa bibliográfica sobre os referenciais teóricos abordados e uma pesquisa exploratória para verificar a existência de Tabelas Periódicas Interativas similares, seguidos de um estudo descritivo e analítico mediante inspeção de duas tabelas interativas com base na técnica Clínica de Design, de Gui Bonsiepe (2011), para avaliar interfaces gráficas mediante três grupos de critérios: (a) referentes às sequências de ações e modos de interação do usuário com o software; (b) relacionados à apresentação das sequências de ação no uso do software, vale dizer, os aspectos comunicativos e perceptivos; (c) ligados às qualidades de agradabilidade da interface.

Na Figura 1 tem-se a ilustração da Tabela Periódica Interativa.

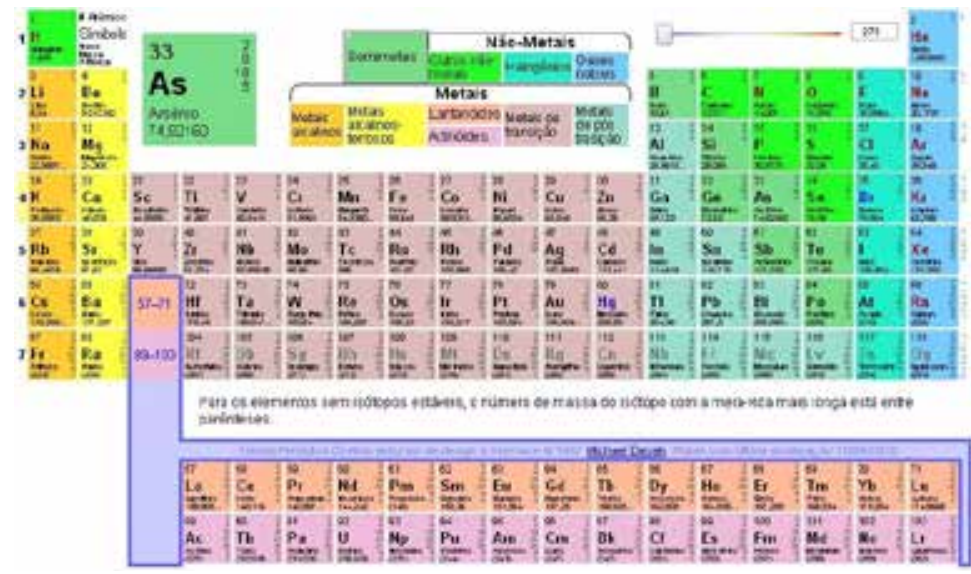

Figura 1: Tabela Periódica Interativa

Fonte: https://www.ptable.com

\section{a) Refere-se ao manejo do aplicativo}

A funcionalidade da tabela baseia-se em duas técnicas: ao clique e ao mouseover. No acionamento por meio de um clique, os símbolos dos elementos químicos precisam ser selecionados para o usuário poder visualizar o conteúdo detalhado sobre cada um deles. Esse conteúdo é exibido em uma janela estilo lytebox que abre sobre a tabela de forma ampliada.

Já o efeito mouseover é realizado passando o mouse por cima das áreas dos elementos, sendo o seu conteúdo disponibilizado no topo da tabela. Nessa área em que o conteúdo é dinâmico são apresentadas em tamanho ampliado as categorias das quais o elemento faz parte (metal, não metal), a sigla, o nome, a massa atômica e o número atômico. Todas as categorias ficam visíveis e, ao escolher passar o mouse sobre outro elemento, observa-se o deslocamento de uma borda preta de seleção em cima do novo elemento químico selecionado e de sua categoria correspondente.

Existe uma numeração no eixo $x$ e y da tabela que contribui com a interação, pois, além de servir como um localizador de posição, também seleciona toda a linha ou toda a coluna da tabela ao ser acionada.

No topo da página da tabela aparecem quatro checkboxes (massa, nome, elé- 
trons, largo) que, ao estarem habilitados, exibem na tela principal da tabela os valores correspondentes a cada elemento. Ao desabilitar um checkbox, a informação some da tela, podendo deixar o layout mais clean ou mais carregado de informações.

Outras funcionalidades observadas que agregam valor à apresentação e apresentam conteúdos mais complexos na tabela são: (1) cursor adaptativo de temperatura; (2) link para informações quanto a 'propriedades', 'orbitais', 'isótopos' e 'componentes'; e (3) um campo de busca.

Não foram encontradas mensagens de erro. Existe uma mensagem de feedback orientando o usuário quanto à interação para visualizar mudanças na tabela. Existe um link no topo da página que apresenta várias explicações sobre ela, assim como um link que disponibiliza versões para impressão da tabela em .jpg e .pdf.

\section{b) Refere-se às características formais e à distribuição dos itens em tela}

As informações são distribuídas por três menus principais, o logo e a tabela em si. Um menu de seleção de idioma. Outro menu mais geral com links para contato, sobre, impressões. E outro menu no formato de abas que altera informações na tabela ao ser acionado pelo usuário na interação.

Quanto à tipografia, é utilizada uma fonte comum, sem serifa, em toda a interface, conforme o padrão web de famílias tipográficas (Arial, "Arial Unicode MS", sans-serif).

As cores utilizadas nessa tabela periódica, de fundo branco, são fluorescentes, alegres e chamam bastante a atenção. Os elementos básicos utilizados são textos, palavras e siglas; não foram utilizados ícones. Há a opção de passar a tabela para diversos idiomas através de um select de país. A única imagem aparece no acionamento da aba Orbitais.

A estratégia utilizada na apresentação da tabela é esconder determinadas informações mais complexas para dar liberdade ao usuário em exibi-las ou não. A tabela apresenta bastante conteúdo, minimizado em abas, links e opções de clique 'habilitar' e 'desabilitar' para públicos de nível básico até nível avançado com conhecimentos mais aprofundados nessa área da Química. São empregadas na tabela as legendas, as informações complementares e várias descrições.

\section{c) Refere-se às qualidades de agradabilidade}

A interface apresenta um conteúdo complexo, compreendendo várias opções de acionamento que a tornam dinâmica, instigante e coerente. É agradável, mas um pouco cansativa pelo volume de informações técnicas.

A aparência da tabela é minimalista, tendendo ao flat design: sem sombras e bordas; linhas retas; e layout clean.

Na Figura 2 tem-se a ilustração da Tabela Periódica de Elementos com figuras e palavras. 


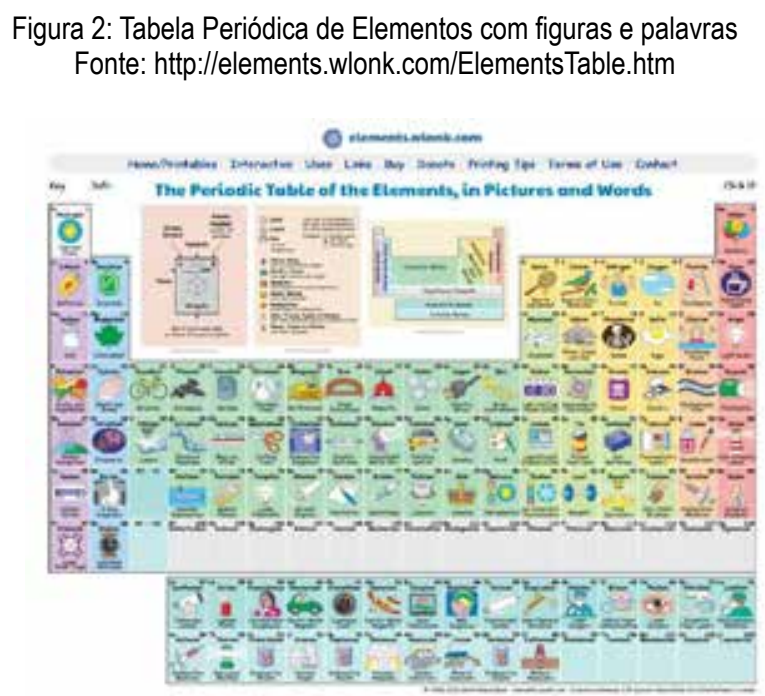

\section{a) Refere-se ao manejo do aplicativo}

A interação ocorre quando você clica sobre um elemento químico da tabela. A informação é exibida na área do topo, dividida em três blocos: (1) informação ilustrada em que o elemento pode ser encontrado aplicado em produtos; (2) informação textual sobre outras formas e lugares em que o elemento pode ser encontrado; (3) informação textual sobre a categorização e o tipo de grupo ao qual o elemento químico pertence, conforme ilustrado na Figura 3.

Figura 3: Elementos representativos da cultura surda Fonte: Adaptada de: http://elements.wlonk.com/ElementsTable.htm

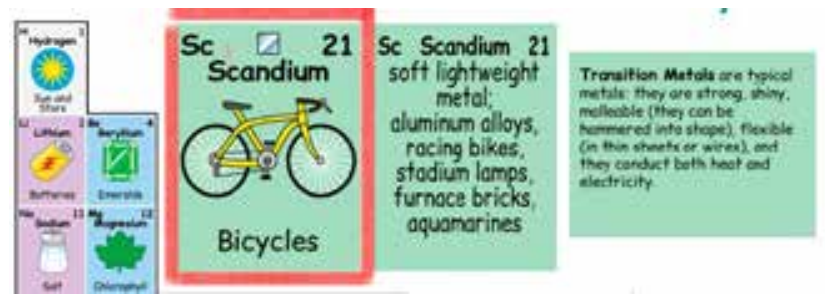

Ao clicar em cima de um dos três quadros ilustrados, uma janela ampliada aparece sobre aquela parte da tabela com as informações num formato de lytebox. Sabe-se que o usuário clicou no elemento através de uma borda azul, delgada e discreta, que fica selecionando a área ativa do último clique efetuado.

Outras funcionalidades foram adicionadas a essa tabela para ampliar o acesso a informações mais detalhadas ou complementares, como (1) link para sugestões de referenciais teóricos; (2) versões impressas da tabela em vários modelos; (3) versão de formato de cards com os elementos químicos ilustrados; e (4) link para uma página com dados das tabelas quanto a descrições, usos e ocorrências detalhadas com base em cada elemento.

Não foram encontradas mensagens de erro. Existe uma mensagem de feedback orientando o usuário a clicar na tabela e iniciar a interação. Também existe um link no topo da página que disponibiliza várias versões e modelos para impressão da tabela. 


\section{b) Refere-se às características formais e à distribuição dos itens em tela}

Pode-se observar uma composição diferente para a Tabela Periódica, desenvolvida com predominância de imagens. As ilustrações utilizadas não eliminam o texto, mas servem como um apoio visual e autoexplicativo que facilita a compreensão das informações de forma mais lúdica e atrativa.

As informações são distribuídas por um menu principal no topo, um menu secundário de dois links (key e Info), a área do logotipo e a tabela em si, todos alinhados ao centro da página, além da divisão em três blocos de mesma cor para exibir o conteúdo de cada elemento no topo da tabela.

No caso das cores, observa-se a utilização de cores frias e discretas para que essas não chamem mais a atenção do que a informação em forma de desenho. As cores empregadas nessa tabela são diferentes das comumente utilizadas em tabelas periódicas em materiais impressos.

\section{c) Refere-se às qualidades de agradabilidade}

A interface traz um conteúdo simplificado, lúdico e atrativo. É agradável a forma como a informação é apresentada. As ilustrações grandes e coloridas despertam a curiosidade, o interesse e o prazer em navegar pela interface.

A aparência da tabela, devido à mistura das cores das caixas dos elementos químicos com a variedade das cores das ilustrações, a torna um pouco poluída visualmente. As ilustrações são bastante detalhadas, buscando uma representação mais real, possuem contorno e sombra.

\subsection{Requisitos e recomendações para a Tabela Periódica Interativa Bilíngue}

A partir das pesquisas e da analise das duas tabelas periódicas interativas, indica-se a inserção de três funcionalidades como requisito básico para compor a Tabela Periódica Bilíngue. São elas: uma versão para impressão simplificada da tabela; exercícios para que o aluno possa fixar o conteúdo; e um glossário dos termos mais utilizados no ensino médio.

O glossário deverá ser inserido na tabela periódica para ampliar as informações fornecidas, visando contribuir com a contextualização e o entendimento do conteúdo de forma mais didática e imersiva. Além da tradução de cada elemento químico, inicialmente será disponibilizada a tradução também de 24 termos do português para LIBRAS, os quais são recorrentes nos materiais explicativos da tabela periódica. Esses foram extraídos da análise e listados na Tabela 1. 
Tabela 1: Tradução de palavras do português para LIBRAS

\begin{tabular}{|l|c|c|c|}
\hline Alcalinos & $\begin{array}{c}\text { Elementos de } \\
\text { transição }\end{array}$ & Nome & Pós-transição \\
\hline Átomos G & ases nobresM & oléculas & Química \\
\hline Actinídeos & Halogênios & Número atômico & $\begin{array}{c}\text { Reação } \\
\text { química }\end{array}$ \\
\hline Classificação & LantanídeosN & ão-metaisS & ímbolo \\
\hline Elétrons & Massa atômicaP & eso atômico & $\begin{array}{c}\text { Tabela } \\
\text { Periódica }\end{array}$ \\
\hline Elementos & Metais & Propriedades & Transformaçã \\
\hline
\end{tabular}

As pesquisas realizadas confirmam a importância de manter as informações básicas que constam nas tabelas ilustradas nos livros didáticos, apresentando a classificação e a propriedade dos elementos químicos. Devem aparecer o símbolo do elemento químico, seu nome e seu número atômico para que não haja perda de informações e prejuízo na ação educativa de construção do conhecimento em relação aos alunos ouvintes.

Além disso, a exemplo de uma das tabelas analisadas, a disponibilização das informações será ampliada, abordando também a utilidade, com ilustrações de onde o elemento químico pode ser encontrado no dia a dia, o que deve melhorar a apresentação das informações de acordo com a forma visual de percepção do surdo e também os processos cognitivos de associação que o usuário pode fazer entre sinal, palavra e desenho.

Quanto ao conteúdo abordado, para complementar as informações disponibilizadas, são de grande valia que sejam inseridos dois vídeos em LIBRAS com legenda em português apresentando a história das tabelas periódicas e a história dos elementos químicos.

Para a estrutura da tabela periódica, o estudo leva à crença da necessidade de que cada elemento químico em texto possua o seu sinal correspondente traduzido para LIBRAS, a sua escrita em SignWritting, a informação e a sigla em português. Ainda, indica-se a inserção de um link que abra em uma janela flutuante e exiba informações complementares adicionadas, como um exemplo do material aplicado no dia a dia do aluno.

A exibição do conteúdo de exemplo do material aplicado pode ser em forma de vídeo, GIF animado ou ilustrações estáticas, garantindo o caráter hipermidiático ao fazer uso de vários recursos gráficos. Além disso, a interação da tabela não será feita por clique e por efeito mouseover para que, quando o usuário observar um elemento, não perca o contexto visual com os demais elementos. Assim, ao passar o mouse por cima dos elementos, ele possa ver as informações correspondentes a cada um deles de forma interativa.

Para que o sentimento de pertencimento e identificação do surdo seja imediato ao visualizar a tabela pela primeira vez, o estudo indica que na tela principal as ilustrações que foram utilizadas em uma das tabelas analisadas e que causam certa poluição visual possam ser substituídas pelo SignWritting das siglas dos elementos químicos. Os elementos específicos da LIBRAS, na cultura surda brasileira, no contexto bilíngue estão ilustrados na Figura 4. 
Figura 4: Elementos representativos da cultura surda Fonte: Autores.

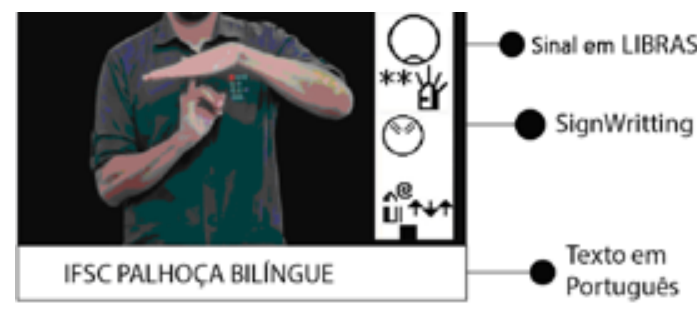

Por fim, até o presente momento os resultados dos estudos realizados conduzem indicativos para o desenvolvimento de uma Tabela Periódica Bilíngue com dados básicos de forma contextualizada e atrativa, com o auxílio de recursos audiovisuais, como fotos e vídeos, para a apresentação de informações complementares do conteúdo.

\section{Considerações finais}

O estudo de interfaces gráficas para a educação de surdos com foco no Design da Informação possibilita a melhoria da qualidade da apresentação e disponibilização do conteúdo didático. Assim, ao inserir elementos da cultura surda na interface de forma interativa e planejada, podem-se facilitar a percepção e a leitura das informações, potencializando o aprendizado dos alunos surdos mediante uma experiência prazerosa.

A inserção na interface dos sinais, da língua de sinais escrita, do uso de ilustrações, de vídeos, de textos curtos, de legendas, de glossário etc. imerge os alunos surdos em um mundo conhecido e contribui com a ampliação da identificação, da motivação e da sensação de pertencimento no contexto educacional.

A proposta de ser uma tabela bilíngue (LIBRAS/Português) levanta a questão do uso da língua do surdo como primeira língua no material didático, mas não invalida o português nem impede que os ouvintes tenham acesso e compreensão, indo ao encontro do bilinguismo almejado dentro do IFSC Palhoça Bilíngue (Libras/Português).

As pesquisas já existentes até então na área da Química voltada ao ensino médio apresentaram contribuições que caminham para traduções de termos da disciplina de Química em meios físicos. Porém, a transposição dessas informações, com o olhar do design, para um protótipo de Tabela Periódica Interativa Bilíngue não foi encontrada, configurando-se assim numa proposta de estudo inovador no campo da pesquisa.

Para a continuidade deste estudo, deverão ser realizadas pesquisas com os alunos surdos mediante aplicação de questionários para investigar as preferências quanto a ilustrações, cores e interações, além da realização de teste de usabilidade com o protótipo on-line.

Espera-se que a Tabela Periódica Interativa Bilíngue seja desenvolvida e atenda às especificidades do público surdo e que, estando disponível na internet, sirva como suporte da ação pedagógica como um material didático auxiliar não só para os alunos do campus Palhoça, mas para todos os surdos do Brasil. 


\section{REFERÊNCIAS}

AMBROSE, Gavin; HARRIS, Paul. Layout. Porto Alegre: Bookman, 2012.

BONSIEPE, Gui. Design, cultura e sociedade. São Paulo: Blucher, 2011.

BRASIL. Plano Nacional de Educação 2014-2024. Lei n. 13.005, de 25 de junho de 2014, que aprova o Plano Nacional de Educação (PNE) e dá outras providências. Brasília: Câmara dos Deputados, 2014. Disponível em: <http://www.observatoriodopne. org.br/uploads/reference/file/439/documento-referencia.pdf>. Acesso em: 14 jun. 2017.

COSTA, Edivaldo da Silva. O ensino de Química e a Língua Brasileira de Sinais - Sistema SignWriting (LIBRAS-SW): monitoramento interventivo na produção de sinais. Dissertação (Mestrado em Ensino de Ciências e Matemática) - Programa de Pós-Graduação em Ensino de Ciências e Matemática, Universidade Federal de Sergipe, São Cristovão, 2014.

ELEMENTS WLONK. Elements Table. Disponível em: <http://elements.wlonk.com/ ElementsTable.htm>. Acesso em: 27 ago. 2017.

FERNANDES, Eulalia; RIOS, Katia Regina. Educação com bilinguismo para crianças surdas. Intercâmbio, v. VII, p. 13-21, 1998. Disponível em: <http://www.gestaoescolar.diaadia.pr.gov.br/arquivos/File/sem_pedagogica/fev_2013/sp2013_anexo17.pdf>. Acesso em: 8 jun. 2017.

FRASCARA, Jorge. Communication design: principles, methods and practice. New York: Allworth Press, 2004.

HORN, Robert. E. Information design: emergence of a new profession. In: JACOBSON, Robert. (Ed.). Information design. Cambridge (MA): The MIT Press, 2000.

LAPOLLI, Mariana. Visualização, conhecimento por meio de narrativas infográficas na web voltadas para surdos em comunidades de prática. 2014. 277 f. Tese (Doutorado em Engenharia e Gestão do Conhecimento) - Programa de Pós-Graduação em Engenharia e Gestão do Conhecimento, Universidade Federal de Santa Catarina, Florianópolis, 2014.

MACHADO, Paulo Cesar. Diferença cultural e educação bilíngüe: as narrativas dos professores surdos sobre questões curriculares. 2009. 164 f. Tese (Doutorado em Educação) - Programa de Pós-Graduação em Educação, Universidade Federal de Santa Catarina, Florianópolis, 2009.

MORAIS, Carla Damaseno; FERRETTI, Cláudio.; MACHADO, Cesar Paulo. Princípios educativos na perspectiva da diferença. Florianópolis: IFSC, 2012. 
PT ABLE. Disponível em: <https://www.ptable.com>. Acesso em: 27 ago. 2017.

RAMIREZ, Alejandro. R. G.; MASUTTI, Mara. L. A educação de surdos em uma perspectiva bilíngue: uma experiência de elaboração de softwares e suas implicações pedagógicas. Florianópolis: Ed. UFSC, 2009.

SALDANHA, Joana. Criação de sinais para o ensino de Química: uma possibilidade real para surdos. In: 34aㅡ REUNIÃO ANUAL DA SOCIEDADE BRASILEIRA DE QUÍMICA - SBQ, 2011, Florianópolis, SC.

SILVA, Vilmar. A luta dos surdos pelo direito à educação e ao trabalho: relato de uma vivência político-pedagógica na Escola Técnica Federal de Santa Catarina. 2001. 142 f. Dissertação (Mestrado em Educação) - Programa de Pós-Graduação em Educação, Departamento de Ciências da Educação, Universidade Federal de Santa Catarina, Florianópolis, 2001.

SKLIAR, Carlos. Atualidade da educação bilíngue para surdos. Porto Alegre: Mediação, 1999. v. 2.

SOUSA, Mauro Wilton. O pertencimento ao comum mediático: a identidade em tempos de transição. Significação, São Paulo: ECA/USP, n. 34, p. 31-52, 2010. Disponível em: <http://www3.usp.br/significacao/pdf/Significacao34_2\%20Mauro\%20Wilton\%20de\%20Sousa.pdf>. Acesso em: 15 jun. 2017. 